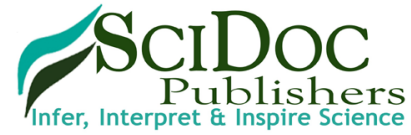

\section{Unintentional Celebratory Gunshot to a 3-year-old Child with Injury to Deep Circumflex Iliac Artery - A Rare Case Report}

\author{
Mandal $\mathrm{SP}^{1^{*}}$, Senthil $\mathrm{KR}^{2}$, Vaishnav $\mathrm{D}^{3}$ \\ ${ }^{1}$ Additional Professor, Department of Forensic Medicine, PGIMER, Chandigarh, India. \\ ${ }^{2}$ Senior Resident, Department of Forensic Medicine, PGIMER, Chandigarh, India. \\ ${ }^{3}$ Junior Resident, Department of Forensic Medicine, PGIMER, Chandigarh, India.
}

\title{
Abstract
}

Celebratory firing is one of the causes of Unintentional firearm injuries. This paper reports a case of a 3-year-old female child who died following gunshot injury sustained in a marriage function she attended with her parents. The bullet entered from the right upper abdomen and injured deep circumflex iliac artery on the left side before perforating the left iliac blade and leaving the body. The rarity of the vessel injury caused the clinician to miss the hemoperitoneum initially which lead to hemorrhagic shock and finally death. This article discusses the mechanism of gunshot injury sustained by the girl, and also urges the government to implement strict laws to prevent such kind of accidents in the future.

Keywords: Unintentional Firearm Injuries; Celebratory Firing; Deep Circumflex Iliac Artery; Hemoperitoneum; Hemorrhagic Shock.

\section{Introduction}

Celebratory firing is one of the causes of accidental firearm related injuries in India [1]. Though some states have banned it after some fatalities reported at marriage functions and festivals, in many states of North India, people still practice this as a custom. We report such kind of firearm injury to a female child. She died due to haemorrhagic shock following injury to the deep circumflex iliac artery, a rare kind of injury to be reported in an accidental gunshot fatality.

\section{Case Report}

A 3-year-old girl was brought to the Pediatric Emergency Department of PGIMER, Chandigarh with an alleged history of firearm injury in a marriage function held in the North Indian state of Haryana. Immediately she was taken to a local hospital where the wound was cleaned and stitched. The ultrasound taken at that time was normal, and after 12 hours of the conservative treatment, she was shifted here as per the wish of her parents.
She arrived the Emergency room with a feeble pulse, tachycardia and her blood pressure was 70/32 $\mathrm{mmHg}$. The abdomen was found distended, tender and guarding rigidity was noted. The $\mathrm{X}$-ray in supine position showed few dilated bowel loops with no metallic foreign bodies. USG examination showed gross free fluid in abdomen and pelvis with oedema of bowel loops. After 9 hours of best efforts to save her life, she succumbed to her injuries. The bleeding organ/vessel was not identified clinically, and cause of death was given as concealed abdominal haemorrhage with compartment syndrome in a case of gunshot injury. The case was shifted to the Department of Forensic Medicine for the purpose of post-mortem examination.

\section{Autopsy Findings}

On examination, a stitched firearm entry wound was noted on the right side of the upper abdomen, $3 \mathrm{~cm}$ above and $5 \mathrm{~cm}$ lateral to the umbilicus. On removing the stitches, the wound measured $0.7 \times 0.6 \mathrm{~cm}$, and a ring of abrasion collar surrounded by a contusion ring was found in and around the margins of the wound. A stitched firearm exit wound was present over the left hip, $1 \mathrm{~cm}$

*Corresponding Author:

Dr. Shatrughan Prasad Mandal,

Additional Professor, Department of Forensic Medicine, PGIMER, Chandigarh, India.

Email: drspmandalpgi@gmail.com

Received: Mav 26, 2017

Accepted: June 27, 2017

Published: July 04, 2017

Citation: Mandal SP, Senthil KR, Vaishnav D (2017) Unintentional Celebratory Gunshot to a 3-year-old Child with Injury to Deep Circumflex Iliac Artery - A Rare Case Report. Int J Forensic Sci Pathol. 5(4), 357-359. doi: http://dx.doi.org/10.19070/2332-287X-1700078

Copyright: Mandal SP ${ }^{\circ}$ 2017. This is an open-access article distributed under the terms of the Creative Commons Attribution License, which permits unrestricted use, distribution and reproduction in any medium, provided the original author and source are credited. 
below the anterior superior iliac spine. On removing the stitches, It measured $1.3 \mathrm{~cm} \times 0.7 \mathrm{~cm}$ and the wound margins are everted. The track starts from the right upper abdomen, perforating skin, subcutaneous tissues, muscles of the anterior abdominal wall, peritoneum and enters into the peritoneal cavity. There was no injury to abdominal organs and intestine except slight oedema of bowel loops. Pelvic and peritoneal cavities are filled with fluid and clotted blood and the internal organs were pale. On exploration to find the bleeding source, it was found that the Deep Circumflex Iliac artery near anterior superior iliac spine (ASIS) was injured. A bony hole of diameter, $0.6 \mathrm{~cm}$ with outward displacement of a bone chip was present in the upper anterior aspect of left iliac bone near ASIS. The track ended by producing an exit wound on the left hip, $1 \mathrm{~cm}$ below the ASIS. No metallic projectile was found and the cause of death, in this case, was given as Haemorrhagic shock consequent to projectile perforating injury in an alleged case of firearm injury.

\section{Discussion}

Among the US children and teens, firearm injury is a leading cause of death, and among the age group of 15-19 years, it is the second leading cause. Considering the age group of 1-9 years, it is the seventh leading cause of death. According to National Violent Death Reporting System (NVDRS) 2009, unintentional firearm death disproportionately affects youth and the reported incidence was $1.1 \%$. Among these deaths, thirty percent were distributed among the age of 0-9 years [2]. In India, one study showed that accidental firearm injuries are common among children and the most common cause was ceremonial firing [1].

Many cases of celebratory firing have been reported previously in news medias and scientific journals. MK Bora et al., reported a case of accidental bullet injury of a 30-year-old male. The bullet hit him in the face when he was dancing in a marriage party at

Figure 1.

A: A Stitched entry wound onright side of the upper abdomen.

B: An exit wound on left hip.

C: Peritoneal cavity filled with blood.

D:Probe showing the track of the bullet.
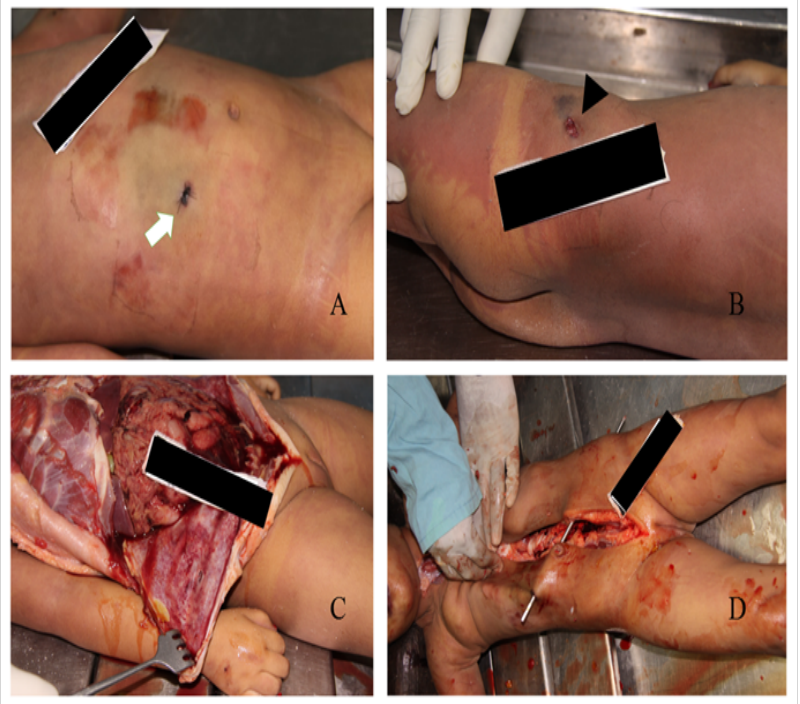

Jaipur. In this part of Rajasthan firing in the air is a social custom during the wedding [3]. A 5-year girl lost her life in a celebratory firing at Amritsar in September 2015 [4]. A 28-year old male who was the groom of a marriage function was shot dead in Uttar Pradesh, a northern state of India. According to a news report, he fell from his horse following some shots were fired in the air by his relatives during the function [5]. A 25-year-old pregnant dancer was shot dead during a marriage in MaurMandi, Bhatinda located in the Northern state of Punjab. On $3^{\text {rd }}$ December 2016, she was shot dead by a frustrated intoxicated man following her refusal for dancing with him. A day after this incidence Haryana government has banned celebratory firing with immediate effect [6]. It is not banned in many states of India, despite the various courts of India has convicted the accused under section IPC 299 and IPC 304 with maximum imprisonment of seven years [7-9].

Celebratory firing is commonly practised among the people of North India, particularly in Punjab, Haryana, UP, Bihar and Rajasthan. Firing off a gun at marriage, birthdays and other local festivals is considered as a status symbol among the affluent class. Politicians after winning elections and other rich people do celebratory firings to demonstrate their power to their followers. In India Celebratory Firearm-related injuries are more common during the months of March, April and July as most of the marriages and elections are held during these months. The present case was also reported in the month of April. Most of the time these mishappenings are due to mishandling of gun under the influence of alcohol or drugs, or the person is not trained to handle the gun well [1]. In the present case, some months after the autopsy, a video clip of the marriage function was shown by the investigating officer to the author. The bride was standing on the stage along with her relatives. Two persons standing beside the bride were carrying guns, one has a shotgun and another having a handgun. First, the shotgun was fired in the air following which many persons in the crowd including the bride and the person who is carrying the handgun showed a jerk as a shock reaction. Due to this sudden jerky movement of the body, the person holding the handgun accidentally fired in a downward direction towards the 
spectators sitting in front of the stage, which was clearly followed by a child's cry. The clip clearly showed that the shot was unintentional and ruled out the homicidal angle.

Another interesting aspect of this case is the rarity of the vessel that got injured. The Deep Circumflex Iliac Artery (DCIA) is a branch of the external iliac artery, and it originates in the region of the inguinal canal. It then runs laterally and upwards toward the anterior superior iliac spine (ASIS) for approximately 5 to 7 $\mathrm{cm}$. At the level of ASIS, it gives a large ascending branch which pierces the transverse abdominal muscle and lies between it and the internal oblique muscle [10]. Injury to the DCIA is very rarely reported in the literature. The causes are Traumatic and spontaneous rupture of DCIA. Neo et al., reported a case of abdominal wall haemorrhage following the rupture of a pseudoaneurysm of the DCIA formed at an anterior iliac bone graft donor site [11]. Trauma may be due to direct injury to the abdominal wall or various surgical procedures like anterior iliac bone harvesting. The injury usually causes retroperitoneal or abdominal wall hematoma. Lefere et al., reported a case of expanding lateral abdominal wall hematoma following the rupture of the DCIA in blunt abdominal trauma. The hemoperitoneum due to injury to DCIA is very rarely reported [12]. Parl SW et al., reported a case of DCIA related hemoperitoneum due to surgical drain placement after liver transplantation. They successfully treated the case with Transcatheter embolization of the branches of the DCIA by using Nbutyl cyanoacrylate [12]. In the present case, the deceased initially taken to a local private hospital where the vascular injury has not been detected. She was under observation for about nine hours after stitching the entry and exit gunshot wounds. When she was brought to the higher centre, her vitals were severely compromised and later she succumbed to her injuries. On Autopsy it was found that the bullet entered from the right upper quadrant of the abdomen, penetrated peritoneum and travelled superficially without damaging any abdominal and pelvic organs. On the left side, it injured DCIA and made a hole in the iliac bone near ASIS and left the body. In this case, an early angiogram followed by transcatheter embolization could have saved this child's life. The rarity of this vascular injury made the clinician to miss the diagnosis.

\section{Conclusion}

The celebratory firing is widely practised among the people of the northern part of India despite the restrictive measures taken by the government to abolish this practice. Many fatal cases were reported recently, and it shows the poor implementation of laws laid by the government of various states of India. This case report shows the danger caused by celebratory firing and also reports the rarest type of injury to the deep circumflex iliac artery which caused hemoperitoneum. This report urges the government to ban celebratory firing in all the states of India to avoid such kind of fatality in future.

\section{References}

[1]. Khan I, Shakeel M, Singh P, Usmani JA, Hasan SA (2013) Trends In Firearm Injuries Related To Accidental Causes: A Study.

[2]. Faulkenberry JG, Schaechter J (2015) Reporting on pediatric unintentional firearm injury-Who's responsible. J trauma acute care surg. 79(3): S2-8.

[3]. Bora MK, Narwani S, Mishra P, Bhandari A (2002) A bullet in the parapharyngeal space. Indian J Otolaryngol Head Neck Surg. 54(1): 46-7.

[4]. Service T. Use of firearms in marriage palaces goes unabated. Tribuneindia News Service. February, 2017.

[5]. Jigmey Bhutia (2016) Celebratory firing kills groom in India's Uttar Pradesh. International Business Times UK. 2016 [cited 28 February 2017].

[6]. Rohan Dual TNN (2016) Pregnant dancer killed at a marriage in Bathinda. The Times of India News.

[7]. Kunwar Pal, Criminal Appeal No. 1643 of 2013, State of Uttarakhand, Supreme court of India.

[8]. Suresh kumar S, Criminal revision No. 2414 of 2015, State Of Uttar Pradesh. High court of India.

[9]. Jasbir Singh, Criminal Appeal No. 554 of 2015, Supreme court of India.

[10]. Park SW, Chang SH, Yun IJ, Lee HW (2010) Deep circumflex iliac arteryrelated hemoperitoneum formation after surgical drain placement: Successful transcatheter embolization. Cardiovasc intervent radiol. 33(2): 402-5.

[11]. Neo M, Matsushita M, Morita T, Nakamura T (2000) Pseudoaneurysm of the deep circumflex iliac artery: a rare complication at an anterior iliac bone graft donor site. Spine. 25(14): 1848-1851.

[12]. Lefere P, Gryspeerdt S, Van Holsbeeck B, Baekelandt M (1999) Diagnosis and treatment of expanding haematoma of the lateral abdominal wall after blunt abdominal trauma. Eur Radiol. 9(8): 1553-1555. 